\title{
Correction to: Conclusion: Ron Eyerman and the Study of Cultural Trauma
}

\section{Correction to:}

Chapter 9 in R. Eyerman, Memory, Trauma, and Identity, Cultural Sociology, https://doi.org/10.1007/978-3-030-13507-2_9

The original version of the chapter has been revised with the following corrections:

Conclusion for this book was contributed by another author "Eric Taylor Woods", but it shows as authored by Ron Eyerman (the book's author). So the author information in the Chapter 9 has been changed to "Eric Taylor Woods" with email id "e.t.woods@uel.ac.uk" and affiliation "University of East London, UK".

The final corrections have been incorporated. 